\title{
A study on new market development using a hybrid of QFD and ANP
}

\author{
Seyedeh Rashedeh Makhzan Mousavi ${ }^{\mathrm{a}^{*}}$ and Zahra Alipour Darvishi ${ }^{\mathrm{b}^{*}}$
}

${ }^{a}$ Department of Management and Social Sciences, Islamic Azad University, Tehran North Branch Tehran, Iran ${ }^{b}$ Department of IT Management, Electronic Branch, Islamic Azad University, Tehran, Iran

\section{H R O N I C L E}

Article history:

Received January 4, 2014

Accepted 1 June 2014

Available online

June 112014

Keywords:

Critical success factors

Knowledge management

New product development

\section{A B S T R A C T}

This paper presents an empirical investigation on new product development (NPD) using a hybrid of quality function deployment (QFD) and analytical network process (ANP). The study is accomplished in one of the biggest auto producers in Iran named Saipa. The study examines whether or not NDP influences positively on critical success factors (CSF) and knowledge management (KM). The study also examines whether KM influences on success of NPD. Using some statistical tests, the study confirms that NDP influences on CSF and KM and there is a positive and meaningful relationship between KM and success of NPD. In addition, the study has prioritized various factors for development of new product development and determined that "technology application consistent with customer's needs" as well as "Having various meetings with different departments" are the most important factors for the success of new product development.

\section{Introduction}

One of the necessary steps for new product development is to focus on key factors such as knowledge management (KM) and detecting critical success factors (CSF). There are literally many studies on how to detect such factors (Alavi \& Leidner, 1999; Cavusgil et al., 2003; Cardinal et al., 2001). Gupta and McDaniel (2002), for instance, investigated the link between the KM in contemporary firms and the development of a sustainable competitive advantage. Goh (2002) explored CSF influences on the ability to transfer knowledge, which is an important area of KM. He discussed each of these factors separately and then integrated them into a conceptual framework to explain how effective knowledge transfer could be managed in an organization. Adams and Lamont (2003) examined the roles that absorptive and transformative capacity played in organizational innovation, with specific emphasis placed on the role and effectiveness of KM systems as a determinant of innovation practices. Aranda and Molina-Fernández, (2002) presented a model for detecting innovation degree in service industries. They developed the model under the KM theory lens. Therefore, they considered 
knowledge flows and knowledge integration capabilities of the organization's members as a necessity for the innovation processes to be successfully implemented. They reported the strong explanatory power of innovation intensity with knowledge theory-based models. Badii and Sharif (2003) investigated the relationship between information management and knowledge integration for enterprise innovation.

Bates and Khasawneh (2005) investigated the relationship between organizational learning culture, learning transfer climate, and organizational innovation. The aim was to examine the ability of learning organization culture to account for variance in learning transfer climate and subsequent organizational innovation, and to study the role of learning transfer climate as a mediator between learning organization culture and innovation. They reported that organizational learning culture could forecast learning transfer climate, and both these factors accounted for substantial variance in organizational innovation.

Brockman and Morgan (2003) studied the role of existing knowledge in new product innovativeness and performance. They provided a more thorough assessment of the link between existing knowledge and organizational performance than currently exists in the literature. They detected factors and processes influential in the management of existing knowledge within the areas of learning culture, knowledge building, and organizational performance.

Chen et al. (2004) designed a measurement model and a qualitative index system of intellectual capital (IC) to provide a good tool for enterprises to manage their IC. In their survey, IC was classified into human capital, structural capital, innovation capital and customer capital, and thereupon a qualitative index system for the above four IC elements was designed through an analysis of their contents. They reported that there was a significant relationship between the scores of the four IC elements of a firm and its business performance, which proves the validity and rationality of the IC measurement model and the qualitative index system.

\section{The proposed study}

This paper presents an empirical investigation for new product development (NPD) using a hybrid of quality function deployment (QFD) (Akao, 2004) and analytical network process (ANP) (Saaty, 2001). There are three hypotheses associated with the proposed study of this paper.

1. There is a meaningful relationship between NDP and CSF.

2. There is a meaningful relationship between NDP and KM.

3. There is a meaningful relationship between $\mathrm{KM}$ and success in CSF.

In order to examine the hypotheses of this survey we first rank important factors based on ANP method. The proposed study of this paper has been accomplished among some selected experts who worked for Saipa group, located in Iran. The study has detected six factors including reliability, market share, quality improvement, increase in automation, trouble shooting and increase in product life. Table 1 shows details of the ranking.

Table 1

The results of ranking six factors

\begin{tabular}{lcccccc}
\hline Factor & Reliability & $\begin{array}{c}\text { Market } \\
\text { share }\end{array}$ & $\begin{array}{c}\text { Quality } \\
\text { improvement }\end{array}$ & $\begin{array}{c}\text { Increase in } \\
\text { automation }\end{array}$ & $\begin{array}{c}\text { Trouble } \\
\text { shooting }\end{array}$ & $\begin{array}{c}\text { Increase in } \\
\text { longevity }\end{array}$ \\
\hline Rank & 0.1832 & 0.2987 & 0.1053 & 0.0813 & 0.1306 & 0.2008 \\
\hline
\end{tabular}

As we can observe from the results of Table 1, market share is the most important factor followed by increase in product life, reliability, trouble shooting, quality improvement and increase in automation. 
Next, for new product development, the study has detected eight factors for new product development and Table 2 shows details of our findings.

Table 2

Factors influencing on new product development

\begin{tabular}{ll}
\hline Factor & Description \\
\hline 1 & Team of experts and consultants in new product development \\
2 & Having various meetings with different departments \\
3 & Availability of suitable facilities for new product development \\
4 & Flexibility and availability \\
5 & Marketing strategy \\
\hline 6 & Technology application consistent with customer's needs \\
\hline
\end{tabular}

The proposed study ranks eight factors mentioned in Table 2 and arrange the house of quality for quality function deployment process and the results are summarized in as follows,

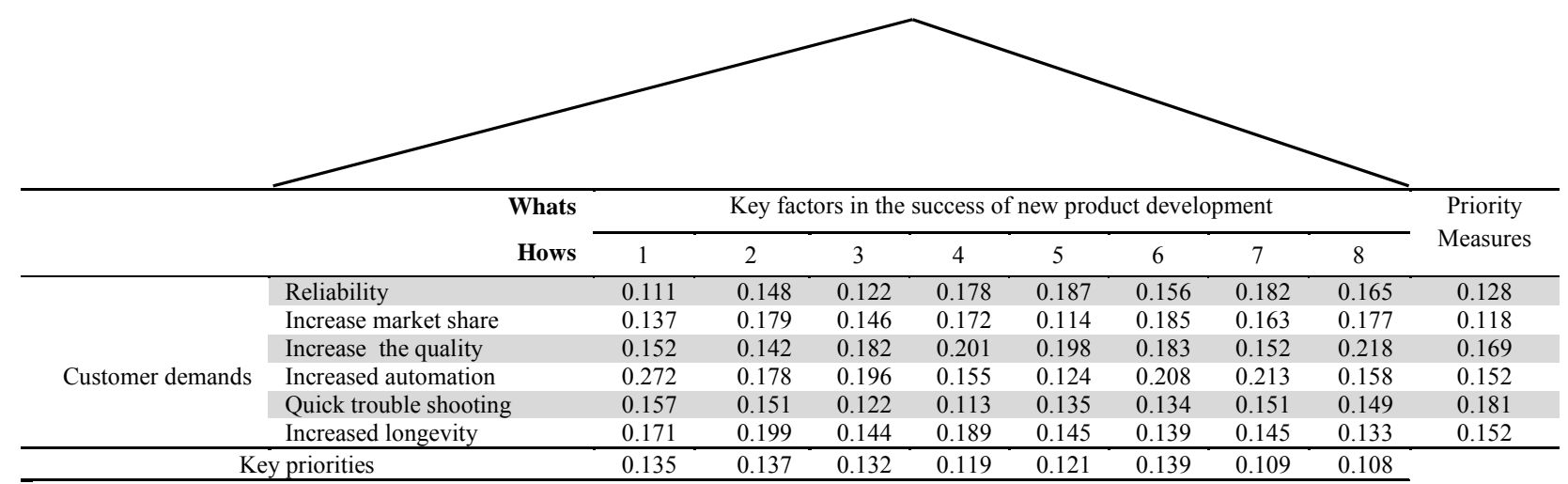

Fig. 1. The results of house of quality

As we can observe from the results of Fig 1., the sixth factor, Technology application consistent with customer's needs, is the first priority followed by the second factor, Having various meetings with different departments. We now present details of examining the hypotheses of the survey.

Table 3

The results of testing various hypotheses

\begin{tabular}{lccc}
\hline Relationship & Estimated $\beta$ & t-value & Sig. \\
\hline CSF $\rightarrow$ NPD & 0.33 & 5.53 & 0.000 \\
KM $\rightarrow$ NPD & 0.49 & 6.42 & 0.000 \\
KM $\rightarrow$ Success of NPD & 0.54 & 7.22 & 0.000 \\
\hline
\end{tabular}

As we can observe from the results of Table 3, all three hypotheses of the survey are confirmed and we can confirm that CSF and KM influence positively on NPD and KM influences on the success in NPD.

\section{Conclusion}

In this paper, we have presented an empirical investigation to study the effect of critical success factor as well knowledge management on new product development and the detected that both variables, CSF and KM, indeed influence positively on new product development. In addition, the study has detected that knowledge management could influence on the success of new product development. In addition, the study has prioritized various factors for development of new product development and determined that "technology application consistent with customer's needs" as well 
as "Having various meetings with different departments" are the most important factors for the success of new product development.

\section{Acknowledgement}

The authors would like to thank the anonymous referees for constructive comments on earlier version of this paper.

\section{References}

Adams, G. L., \& Lamont, B. T. (2003). Knowledge management systems and developing sustainable competitive advantage. Journal of knowledge management, 7(2), 142-154.

Alavi, M., \& Leidner, D. E. (1999). Knowledge management systems: issues, challenges, and benefits. Communications of the AIS, 1(2es), 1.

Akao, Y. (2004). Quality function deployment: integrating customer requirements into product design. Productivity Press.

Aranda, D. A., \& Molina-Fernández, L. M. (2002). Determinants of innovation through a knowledgebased theory lens. Industrial Management \& Data Systems, 102(5), 289-296.

Badii, A., \& Sharif, A. (2003). Information management and knowledge integration for enterprise innovation. Logistics Information Management, 16(2), 145-155.

Bates, R., \& Khasawneh, S. (2005). Organizational learning culture, learning transfer climate and perceived innovation in Jordanian organizations. International Journal of Training and Development, 9(2), 96-109.

Brockman, B. K., \& Morgan, R. M. (2003). The role of existing knowledge in new product innovativeness and performance. Decision Sciences, 34(2), 385-419.

Cavusgil, S. T., Calantone, R. J., \& Zhao, Y. (2003). Tacit knowledge transfer and firm innovation capability. Journal of business \& industrial marketing, 18(1), 6-21.

Cardinal, L. B., Alessandri, T. M., \& Turner, S. F. (2001). Knowledge codifiability, resources, and science-based innovation. Journal of Knowledge Management, 5(2), 195-204.

Chen, J., Zhu, Z., \& Xie, H. Y. (2004). Measuring intellectual capital: a new model and empirical study. Journal of Intellectual capital, 5(1), 195-212.

Goh, S. C. (2002). Managing effective knowledge transfer: an integrative framework and some practice implications. Journal of knowledge management,6(1), 23-30.

Gupta, A., \& McDaniel, J. (2002). Creating competitive advantage by effectively managing knowledge: A framework for knowledge management. Journal of knowledge Management practice, 3(2), 40-49.

Saaty, T. L. (2001). The Analytic Network Process: Decision making with dependence and feedback. RWS Publ.. 